\title{
Removal of 3-Chloroaniline from aqueous solution by Treated Coffee Waste: Isotherm Modelling and Thermodynamic Studies
}

Bandar R. M. Alsehli Alsehli ( $\sim$ bshle@taibahu.edu.sa )

Taibah University

Keywords:

Posted Date: February 12th, 2021

DOl: https://doi.org/10.21203/rs.3.rs-215134/v1

License: (c) (1) This work is licensed under a Creative Commons Attribution 4.0 International License.

Read Full License 


\section{Abstract}

The authors have requested that this preprint be removed from Research Square. 